\title{
DOSAGE DE L'ACIDITÉ DANS LES CASÉINES INDUSTRIELLES
}

\author{
par ANDRÉ CHOLLET. \\ Ingénieur-Agronome, Professeur à l'Ecole de Laiterie de Surgères
}

Dornic et Darre ont indiqué des méthodes exactes et pratiques pour le dosage de l'eau, de la matière grasse et des cendres contenues dans les caséines industrielies (1).

Depuis, la question de l'acidité des caséines a pris, en industrie, une importance de plus en plus grande, mais les méthodes employées diffèrent et les résultats obtenus ne sont souvent pas comparables. D'ailleurs certains chimistes ne se sont pas mis à l'abri d'une cause d'erreur : l'influence de la grosseur des grains de caséine sur les résultats analytiques.

Pour déterminer la teneur en eau d'une caséine il faut la broyer finement avant de la passer à l'étuve sans cela l'eau reste emprisonnée dans le grain; de même pour connaître sa teneur en matière grasse il faut d'abord dissoudre la caséine à chaud dans l'acide chiorhydrique, les méthodes d'épuisement direct par l'éther donnant des nombres d'autant plus élevés que la caséine est en grains plus fins.

Le dosage de l'acidité se heurte à la même difficulté :

Quand on se contente de faire macérer la caséine dans de l'eau pendant un temps plus ou moins long, puis de doser l'acide dissout dans cette eau, avec ou sans filtration, on obtient, pour une même caséine, des nombres différents suivant qu'on opère sur des gros gruaux, des gruaux moyens, des semoules ou des farines.

Voici le procédé que nous avons adopté :

Dans une fiole conique d'environ $50 \mathrm{ce.}$, préalablement séchée et tarée, on pèse deux grammes de caséine à la présure, pulvérisée aussi tinement que possible ou un gramme de caséine lactique également pulvérisée. On ajoute $10 \mathrm{cc}$. d'eau et quelques gouttes de phenolphtaléine ; et on fait tomber dans la fiole, goutte à goutte, la soude de l'acidimètre DoRnIC jusqu'à coloration rouge; on chauffe sur un bee Bunsen, en agitant, jusqu'à décoloration; on rajoute de la soude titrée, on chauffe et on continue ainsi jusqu'à ce qu'on obtienne une teinte rose persistant après refroidissement ; la caséine est alors complètement désagrégée, elle forme une gelée ne présentant plus de grains.

Rappelons que la soude employée dans l'acidimètre DoRnic est de la soude N/9 dont $1 \mathrm{cc}$. neutralise exactement 0 gr. 010 d'acide lactique, et que la burette de l'appareil est graduée en 1/10 de ce. Supposons qu'avec une caséine présure nous ayons employé 4 cc. de soude titrée pour obtenir la teinte rose persistante, les 2 gr. de caséine ont une

(1) Revue Générale du Lait, 30 Juin 1909, p. 328. - Les méthodes ont été reproduites dans Lait, Beurre et dérivés, par Dornic et Chollet, p. 426. 
acidité de $0 \mathrm{gr}$. 04 exprimée en acide lactique et 100 gr. de caséine une acidité de 2 gr., soit $2 \%$.

On peut aussi employer une burette queleonque graduée en $1 / 10$ de cc. et de la soude $\mathrm{N} / 10$; dans ce cas en prenant les $9 / 10$ du nombre trouvé on aura l'acidité exprimée en acide lactique.

Avec ce procédé d'analyse on ajoute l'acidité propre de la caséine à l'acidité due à la présence de l'acide lactique, mais dans la pratique industrielle cela ne parait pas avoir d'importance. Par contre on obtient les mêmes nombres, avec la même easéine, quelle que soit la grosseur du grain. Il y a seulement intérêt à broyer finement les caséines, de façon ì opérer plus rapidement.

La caséine à la présure a, en employant cette méthode, une acidité variant de 1,5 à $3 \%$ suivant que la caillebotte a été plus ou moins bien lavée ; l'acidité de la caséine lactique est le plus souvent comprise entre 6 et $8 \%$.

\title{
LA POUDRE DE LAIT ET L'INDUSTRIE FROMAGËRE
}

\author{
par M. Ch. PORCHER,
}

L'idée n'est pas neuve de faire des fromages avee de la poudre de lait, on peut dire qu'elle est née en même temps que l'industrie du lait desséché.

Bien des essais ont été faits autrefois pour faire des fromages avec du lait sec. Ils ont été plus ou moins heureux, mais il faut reconnaître que l'emploi du chlorure de calcium, préconisé par L. LINDET, lequel donne déjà de si bons résultats dans l'industrie fromagère, ne peutqu'encourager à recourir à la poudre de lait dans la fabrication des fromages.

Dans la $2^{\mathrm{e}}$ édition de mon livre sur le lait desséché (chapitre XIV, pp. 187-190), j'a consacré un court chapitre à la question. Je pense qu'il est intéressant que je le donne ici en son entier, ear il servira d'introduction à l'article qui suit sur un essai de fabrication du fromage avec du lait sec, que j'ai tenté l'an passé, avec le concours de M. DesRantes, de la Société Laitière Moderne de Lyon.

$$
\text { *** }
$$

Si l'on a pensé à faire du lait reconstitué au moyen de la poudre maigre et du beurre, c'était, d'une part, pour répondre aux moments de disette passagère possible, aux accidents provoqués par des chaleurs excessives, quand l'approvisionnement normal en lait frais est troublé et diminué ; c'était, d'autre part, pour sţabiliser le marché des produits de la laiterie, résoudre le problème de l'utilisation d'une surabondance de lait à certaines époques de l'année, et somme toute, savoir utiliser au mieux une marchandise périsable entre toutes et dont la production est malheureusement irrégulière. 